\title{
КУльтУРология
}

DOI 10.17805/ggz.2017.4.4

\section{Субъектность как атрибут экологии культуры}

\author{
Т. Ф. КУЗНЕЦОВА \\ МОСКОВСКИЙ ПЕДАГОГИЧЕСКИЙ ГОСУДАРСТВЕННЫЙ УНИВЕРСИТЕТ
}

В статье субъектность, т. е. порождаемое автономностью и активностью субъекта (индивида или группы) свойство культурного объекта показано в ее становлении от частного случая, соединения случайных обстоятельств рождения культурного объекта, где субъект в полной мере проявляет свои интеллектуальные, образные (в смысле ведущие к созданию образа), эмоциональные качества, до полного отрыва от субъекта с его индивидуальными характеристиками и превращения в культурную константу. Это движение,по мнению автора, и составляет феномен экологии культуры, а субъектность образует ее атрибут. Методологическая сторона этого феномена раскрывается в тезаурусном подходе. Ключевые слова: экология культуры; субъект; субъектность; культурная константа; тезаурусный подход; Вл. А. Луков; культурология

\section{Subjectivity as an Attribute of Cultural Ecology}

\author{
T. F. KUZNETSOVA \\ MOSCOW STATE PEDAGOGICAL UNIVERSITY
}

In the article, subjectivity, i.e. a feature of the cultural object generated by the autonomy and activity of the subject (an individual or a group, from small to arbitrarily large), is shown in its formation from a special case, a combination of accidental circumstances of the birth of the cultural object, where the subject fully displays their intellectual, imaginative (in the sense of leading to the creation of an image), and emotional qualities, to a complete detachment from the subject with its individual characteristics and becoming a cultural constant. This movement, according to the author, constitutes the phenomenon of ecological culture, and subjectivity forms its attribute. The methodological aspect of this phenomenon is revealed in the thesaurus approach.

Keywords: ecology of culture; subject; subjectivity; cultural constant; thesaurus approach; Vladimir A. Lukov; cultural studies

\section{BВЕАЕНИЕ}

Экология, как правило, связывается с вопросами взаимоотношения природы и общества, проблемами природопользования, в том числе экономическими (Гирусов и др., 2007), являясь естественно-научнным или социально-философским знанием. Иначе дело обстоит с экологией культуры (Концепция А. С. Аихачева). Она представляет собой в основном эвфемизм для обозначения сохранения культурного наследия. Как показано В. А. Ауковым, экология культуры не научное понятие, а концепт, на который среди других концептов опирается субъектная организация гуманитарного знания (Иуков, 2017). Концепты в методологии тезаурусного подхода означают «выражаемое в знаке сращение смысла и чувственного восприятия, внутреннего образа» 
(Ауков, Ауков Вл., 2013: 75). Концептом, по существу, следует признать и второе выделенное в рассматриваемом контексте словосочетание, а именно «сохранение культурного наследия». Не может быть однозначно описан такой его элемент, как «сохранение» - не ясно, что из наследия мы сохраняем, сохраняется ли культурный объект при смене его функции, владельца, способа финансирования, установления защитных средств и т. д. Существование аукционов художественных произведений, их перемещение из страны в страну в порядке выставочного и музейного обмена, использование их как залог и прочие действия, не влекущие за собой разрушение объектов культуры, но меняющие их ценность и привычное окружение, можно считать сохранением с большими оговорками. Столь же не ясным оказывается и словосочетание «культурное наследие». Если признавать культурным наследием все, что имело значение в культуре прошлого, то подлежит ли сохранению бросание в пропасть слабых детей у спартанцев, жертвоприношения ацтеков, костры инквизиции в странах Западной Европы, впрочем, и менее кровавые культурные традиции, например, отразившиеся в «Аомострое»?

Однако некоторые стороны экологии культуры могут быть определены, и для этого тезаурусный подход дает большие возможности. Прежде всего, какие культурные объекты избираются для сохранения и в чем это сохранение состоит, определяется культурной картиной мира (Кузнецова, 2012). Неслучайно культурная картина мира в современной культурологии занимает столь важное место (Кузнецова, Ауков, 2009). Картины мира, а они имеют многообразные выражения, которые тем не менее объединяются их назначением как ядра тезауруса (Погорский, 2012), различаются в зависимости от многих обстоятельств (историческое время, этно-национальные особенности, преимущественная религия и т. А.), поэтому культурологию мы представляем в непосредственной связи с историей мировой культуры (Очерки по истории..., 1997; Кнаббе и др., 2003). Но у них есть, как у научной, религиозной и других картин мира, общая черта, а именно прямая связь с субъектом и его тезаурусом: культурная картина мира составляет ядро этого тезауруса.

\section{СУБЪЕКТНОСТЬ И СУБЪЕКТИВНОСТЬ}

Субъектность, в духе тезаурусного подхода к социальной субъектности (Ауков, Ауков Вл., 2008; 2013; 2014), в контексте экологии культуры мы трактуем как порождаемое активностью субъекта (индивида или группы) свойство культурного объекта.

В английском языке субъектность переводят как subjectivity, в немецком как Subjektivität и т. А. (т. е. субъективность и субъектность не различаются), в некоторых языках, например, во французском нет аналогичного слова. Но, заметим, и в русских изданиях (научных в том числе) довольно часто делаются ошибки, когда вместо субъектности ставится субъективность. В чем здесь разница?

В. А. и Вл. А Ауковы пишут: «Субъективность и субъектность в контексте рассматриваемой характеристики тезауруса следует различать. Если субъективность есть антоним объективности и понятна преимущественно через контраст первой в отношении второй, то субъектность не лежит в этом же ряду характеристик и вряд ли может продуктивно противопоставляться некой объектности. Субъектность - вполне объективная характеристика, применяемая к человеку, человеческим общностям и организациям, когда нужно аналитически выявить присущую этим участникам социальной жизни (социокультурных процессов) черту, которую можно назвать независимостью от системы социальности более высокого порядка. Эта независимость выра- 
жается в двух взаимосвязанных свойствах: во-первых, автономности, во-вторых, активности» (Ауков, Ауков Вл., 2013: 35). Эта точная характеристика различий субъектности и субъективности хорошо проясняет специфику культурных феноменов и применима к трактовке экологии культуры. Культурным смыслом обладает и субъективность, особенно в переходные эпохи (Культура в эпоху цивилизационного слома, 2001) но в общем виде именно субъектность как объективное свойство культуры и ее атрибут проясняет обоснованность экологии культуры. Справедливо в этом смысле выделение субъектной культурологии (Ауков, 2008). Здесь применяется иной принцип, чем в различении инстайта и аутсайта в эмпирических исследованиях, где эти характеристики отнесены к исследователю (Merton, 1972). Отмечая эту работу, Ч. К. Аамажаа идет дальше, к общей тенденции субъективизации научного знания в русле укрепления постнеклассического типа научной рациональности. Она показывает, как это проявляется, на уровне методологии, например, Indigenous Methodology (Мамажаа, 2017). В плане субъектной культурологии важно замечание Ч. К. Аамажаа: «Универсализм оказывается бессильным, когда перед исследователем встают не просто иные термины, но и такие мировоззренческие смысловые узлы, которые невозможно “расчленить”, “разложить” на отдельные составляющие, попытаться их “каталогизировать” по чужеродным методикам» (там же: 123). Методологически важным оказывается способность носителя культуры увидеть то, что не дано оценить внешнему наблюдателю. Но это значит и то, что культура разных народов не выстроена по одним и тем же принципам и образцам (Мамажаа, 2012). Субъектная культурология, сосредоточенная на том, какие ценности в мире культуры освоены человеком, позволяет к каждой культуре не применять единый стандарт и изначально считаться с многообразием и структурной несопоставимостью культур.

\section{ПРЕВРАЩЕНИЕ СУБЪЕКТНОСТИ В КУАЬТУРНУЮ КОНСТАНТУ}

Субъектность по началу связана с тем общекультурным фоном, на котором она проявляется. Разумеется, и при жизни может возникать факт признания в сфере культуры. Так, Франческо Петрарка при жизни был удостоен лаврового венка как величайший из поэтов. Правда, он сам на этом настаивал, завидуя увенчанному лаврами Аанте. Аитературные премии, и Нобелевская среди них, близки в том же целевом направлении. Но и в этих случаях обычно за тем или иным произведением культуры стоит заказ, извлечение прибыли из научного открытия, исполнение религиозного долга, влюбленность (нередко несчастная любовь), стремление превзойти кого-то и т. А., а часто и просто случай, который в иной ситуации невозможно не только повторить, но и предположить. Здесь работает именно субъектность - автономность и активность субъекта в выстраивании культурной картины мира. В частном случае, соединении случайных обстоятельств можно видеть рождение культурного объекта, где субъект в полной мере проявляет свои интеллектуальные, образные (в смысле ведущие к созданию образа), эмоциональные качества. Но это еще не феномен культуры и он далек от идеи его сохранения. Чтобы стать таковым, он должен претерпеть существенные изменения, теряя свои случайные черты, нередко и авторство. Собственно, авторство появляется в сфере культуры, как известно, довольно поздно, оно есть в Античности (Сократ, Еврипид, Мирон и т. А.), оно есть в Эпохе Возрождения (Брунеллески, Аеонардо да Винчи и т. А.), но в Средние века оно выражено мало, и пример Псевдо-Аионисия здесь показателен: не случайно уже давно стало ясно, что за сборником «Ареопагики», на который ссылались все стороны средневековых церковных 
дискуссий и влияние которого обнаруживается у крупнейших европейских мыслителей этого времени, стоит неизвестный автор, а догадка о подмене автора на более авторитетного, относящаяся еще к периоду церковных споров, в конце XIX в. была подтверждена (Koch, 1895; Bardenhewer, 1901).

Пример перевода Библии Аютером на немецкий язык показывает, как слово может от конкретной задачи перевода пройти путь к изменению культурной картины мира целых народов. М. Вебер в «Протестантской этике и духе капитализма» показал, что использование $ю$ ютером для перевода слова «призвание» немецкого «Beruf» сыграло роль культурного переворота: немецкое слово означает «профессия», «род занятий», «ремесло», когда оно оказалось обозначением божественного призвания, как следствие чисто лингвистического феномена возникли или укрепились социальные практики, ставящие в центр призвания профессию, хорошо выполненную работу, а, например, не наживу (Вебер, 1990).

Субъективное представление отдельных пейзажистов еще не импрессионизм или видение человека в движении авангардистами - еще не экспрессионизм. Пока эти индивидуальные особенности видения не составляют течения, направления, школы в искусстве, пока субъективность впечатлений, образов не стала достаточно общим состоянием мыслей, они субъективны, но не субъектны. Нас мало интересует барон Фридрих фон Гарденберг, живший в XVIII в. в Саксонии и умерший в 28 лет от туберкулеза, но мы с интересом относимся к Новалису, хотя это одно и то же лицо (Новалис лишь псевдоним), и в романе Новалиса «Генрих фон Офтердинген» нас не столько впечатляет личный жизненный опыт автора (иными словами, жизненный опыт барона из Саксонии), сколько его романтизм как культурная картина мира. Здесь и происходит превращение субъектности в культурную константу, т. е. в то, что и подлежит сохранению в культуре.

Этот переход убедительно показан в шекспироведении, особенно в работах, где используется тезаурусный подход (Гайдин, 2009, 2011; Захаров, Ауков, 2011, 2012). Шекспир демонстрирует переход от субъективности (т. е. набора индивидуальных авторских черт и стечения конкретных обстоятельств, например, работа Шекспира в лондонском театре «Глобус») к субъектности (именно Шекспир выразил дух эпохи, стал субъектом становления в ней определенных культурных картин мира) и далее к культу автора. Культ Шекспира глубоко осмыслен представителями тезаурусного подхода, показано, в частности, что этот культ не мог возникнуть вне утверждения романтического героя и романтической культурной картины мира, что одновременно означает падение классицизма с его культурной картиной мира, в которую Шекспир совсем не вписывался и казался «дикарем».

Авижение к культурной константе в известном смысле включает в себя замену субъективности субъектностью и образования культа деятеля культуры (или культа самого культурного феномена, если авторства нет в исторической памяти, субъект не ассоциирован с личностями). Надо отметить, что субъектность не терпит произвола личности, об этом свидетельствует, в частности, жанровая природа искусства (Ауков, 2006b, 2008), опора классической культуры на «вечные» образы и сюжеты (Гайдин, 2008, 2009b; Ауков, Ауков Вл., 2008; «Вечные» сюжеты и образы..., 2015). Если для образования культурной константы импульс дает личность, то она или стирается, или известна именно как культ, при этом теряются ее многие отличительные черты, как и теряются черты критического отношения к ней современников. Интерес в этом ракурсе представляет А. С. Пушкин (Захаров, Ауков, Ауков, Вл., 2015). Важно и то, что 
такая условная во многом личность обрастает своим миром - более изученном специалистами, но и приобретающем черты, которые этими специалистами и воссозданы по стандартам своего времени (Bate et al.: Электронный ресурс).

Став культурной константой, субъектность перестает быть однозначно национальной, хотя первоначально воспринимается именно таковой (Dobson, 1992). Она peализуется через принцип тезаурусного расширения индивидуального межкультурного пространства (Ауков, Ауков С., 2012) и в условиях информационного общества приобретает интернациональный характер, о чем свидетельствуют МООКи в образовательной сфере (Макаров, 2015, 2016) и появление феноменов типа «Русский Шекспир» (Захаров, 2005, 2008; Zakharov, Lukov, Makarov, Gaydin, 2012).

Превращение субъектности в культурную константу - процесс сложный и длительный. За ним стоят, по видимости, значимые исторические процессы. Иногда они хорошо известны, иногда полны домыслов и мифотворчества, иногда нет никаких исторических привязок у феноменов культуры, а точнее, напластования веков скрыли от нас эти привязки. Пословицы входят в культуру любого народа, но их происхождение, как правило, темно. Однако они составляют те культурные константы, на которых держится менталитет любого народа.

\section{ЗАКАЮЧЕНИЕ}

Субъектность не есть набор частных характеристик, хотя ей может предшествовать соединение случайных обстоятельств рождения культурного объекта, где субъект в полной мере проявляет свои интеллектуальные, образные, эмоциональные качества. Авижение от субъективности через субъектность означает придание действиям субъекта важного значения в культурной картине мира тем сообществом, которое в данный момент эту картину формирует. В общем виде это процесс, ведущий к полному отрыву культурного феномена от субъекта с его индивидуальными характеристиками и превращения его (феномена) в культурную константу. Это движение и составляет смысл экологии культуры, а субъектность как снятая субъективность, с одной стороны, и как актуализированная в изменившихся условиях потребность культурной жизни, с другой, образует ее признак. Такой признак составляет необходимое, неотъемлемое свойство культуры. Это ее атрибут. Одновременно подчеркнем, что это и атрибут экологии культуры, именно субъектность важно поддерживать.

Методологическая сторона этого феномена раскрывается в тезаурусном подходе. Есть основание идею Вл. А. Аукова, возникшую по конкретному поводу, также рассматривать как утерявшую субъективность и сегодня выражающую субъектность гуманитарного знания.

\section{СПИСОК АИТЕРАТУРЫ}

Гайдин, Б. Н. (2008) Вечные образы как константы культуры // Знание. Понимание. Умение. № 2. С. 241-245.

Гайдин, Б. Н. (2009а) Вечные образы как константы культуры (интерпретация «Гамлетовского вопроса») : автореф. дис. ... канд. филос. наук. М. 17 с.

Гайдин, Б. Н. (2009b) Вечные образы в системе констант культуры // Знание. Понимание. Умение. № 2. С. 224-230.

Гайдин, Б. Н. (2011) Вечные образы как константы культуры: тезаурусный анализ «гамлетовского вопроса» : монография. Saarbrücken : Lambert Academic Publishing. 212 c. 
Гирусов, Э. В., Бобылев, С. Н., Новоселов, А. А., Чепурных, Н. В. (2007) Экология и экономика природопользования : учеб. для вузов / под ред. Э. В. Гирусова, В. Н. Аопатина. 2-е изд., перераб. и доп. М. : ЮНИТИ-ААНА ; Единство. 519 с.

Вебер, М. (1990) Избранные произведения : пер. с нем. / сост., общ. ред. и послесл. Ю. Н. Аавыдов; предисл. П. П. Гайденко. М. : Прогресс. 808 с.

«Вечные» сюжеты и образы в литературе и искусстве русского модернизма (2015)/ отв. ред. А. $\Lambda$. Топорков. М. : Индрик. 416 с.

Захаров, Н. В. (2005) Информационно-исследовательская база данных «Русский Шекспир» // Знание. Понимание. Умение. № 2. С. 153-155.

Захаров, Н. В. (2008) Шекспиризм русской классической литературы: тезаурусный анализ : монография / отв. ред. Вл. А. Ауков. М. : Изд-во Моск. гуманит. ун-та. 320 с.

Захаров, Н. В., Ауков, Вл. А. (2011) Культ Шекспира: теория и всемирные масштабы // Известия Самарского научного центра Российской академии наук. Т. 13. № 2. С. 148-154.

Захаров, Н. В., Ауков Вл. А. (2012) Гений на века: Шекспир в европейской культуре. М. : ГИТР. 504 с.

Захаров, Н. В., Ауков, В. А., Ауков, Вл. А. (2015) Араматургия А. С. Пушкина: проблема сценичности : науч. монография. М. : Изд-во Моск. гуманит. ун-та. 412 с.

Кнаббе, Г. С., Кондаков, И. В., Кузнецова, Т. Ф., Ауков Вл. А. (2003) Культурология: История мировой культуры : учеб. пособие / под ред. Т. Ф. Кузнецовой. М. : Издат. центр «Академия». 605 с.

Кузнецова, Т. Ф. (2012) Культурная картина мира: теоретические проблемы : науч. монография. М. : ГИТР. 250 с.

Кузнецова, Т. Ф., Ауков, Вл. А. (2009) Культурная картина мира в свете тенденций развития культурологии // Вестник Международной Академии наук (Русская секция). № 1. С. 66-69.

Культура в эпоху цивилизационного слома (2001) : материалы Международной научной конференции. М. : Научный совет по истории мировой культуры РАН. 824 с.

Цамажаа, Ч. К. (2012) Тезаурусный подход для тувиноведения // Знание. Понимание. Умение. № 2. С. 38-45.

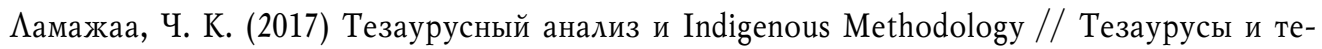
заурусная сфера : II Академические чтения памяти Владимира Андреевича Аукова, 29 марта 2017 г. : сб. науч. трудов. М. : Изд-во Моск. гуманит. ун-та. 256 с. С. 115-126.

Ауков, В. А. (2017) Экология культуры и тезаурусная трактовка будущего [Электронный ресурс] // Горизонты гуманитарного знания. 2017, №3. URL: http://journals. mosgu.ru/ggz/article/view/470 (дата обращения: дА.мм.гггг.). DOI: 10.17805/ggz.2017.3.1

Ауков, В. А., Ауков, Вл. А. (2008) Тезаурусы : Субъектная организация гуманитарного знания. М. : ИзА-во Нац. ин-та бизнеса. 784 с.

Ауков, В. А., Ауков, Вл. А. (2008) Вечные образы как константы тезаурусов мировой культуры [Электронный ресурс] // Информационный гуманитарный портал «Знание. Понимание. Умение». №9 - Комплексные исследования: тезаурусный анализ мировой культуры. URL: http://zpu-journal.ru/e-zpu/2008/9/Lukovs_Eternal_Images/[архивировано в WebCite] (дата обращения: 22.03.2017).

Ауков, В. А., Ауков, Вл. А. (2013) Тезаурусы II : Тезаурусный подход к пониманию человека и его мира : монография. М. : ИзА-во Нац. ин-та бизнеса. 640 с.

Ауков, В. А., Ауков, Вл. А. (2014) Методология тезаурусного подхода: стратегия понимания // Знание. Понимание. Умение. № 1. С. 18-35.

Ауков, В. А., Ауков, С. В. (2012) Принцип тезаурусного расширения индивидуального межкультурного пространства // Тезаурусный анализ мировой культуры : сб. науч. трудов. Вып. 23 / под общ. ред. Вл. А. Аукова. М. : Изд-во Моск. гуманит. ун-та, 2012. С. 10-21.

Ауков, Вл. А. (2006а) Культ Шекспира как научная проблема // Вестник Международной академии наук (Русская секция). № 2. С. 70-72.

Ауков, Вл. А. (2006b) Жанры и жанровые генерализации // Знание. Понимание. Умение. № 1. C. 141-148. 
Ауков, Вл. А. (2008) Культурология объектная и субъектная // Знание. Понимание. Умение. № 1. C. 72-79.

Ауков, Вл. А. (2008d) Культура и социум : Философские вопросы культурной социодинамики : науч. монография. М. : Изд-во Моск. гуманит. ун-та. 104 с.

Ауков, Вл. А. (2011а) Культ Шекспира и шекспиризация в европейском предромантизме // Шекспировские чтения. 2006 / [гл. редактор А. В. Бартошевич; отв. ред. и сост. выпуска И. С. Приходько]; науч. совет «История мировой культуры» РАН. М. : Наука. 469 с. С. 182-196.

Ауков, Вл. А., Захаров, Н. В. (2008) Культ Шекспира как социокультурный феномен // Вестник Международной академии наук Русская секция). № 1. С. 65-68.

Макаров, В. С. (2015) МООКи о Шекспире: британский и российский опыт // Образовательные технологии. № 1. С. 19-27.

Макаров, В. С. (2016) С курсом “Hamlet's Ghost” в мир МООКов входит Стивен Гринблатт [Электронный ресурс]// Современники Шекспира: Электронное научное издание. 30 октября. URL: http://around-shake.ru/news/5056.htm (дата обращения: 25.10.2016).

Очерки по истории мировой культуры (1997) : учеб. пособ. / под ред. Т. ФКузнецовой. М. : Языки русской культуры. 496 с.

Погорский, Э. К. (2012) Картина мира // Знание. Понимание. Умение. № 4. С. 322-323.

Bate, J. et al. Shakespeare and his World [Электронный ресурс] // FutureLearn. URL: https:/ /futurelearn.com/courses/shakespeare-and-his-world [архивировано в WebCite] (дата обращения: 10.04.2015).

Bardenhewer, O. (1901) Patrologie. Breisgau : Freiburg Im Breisgau, Herdersche Verlagsbuchhandlung. $660 \mathrm{~S}$.

Dobson, M. (1992) The making of the national poet: Shakespeare, adaptation and authorship, 1660-1769. Oxford : Clarendon Press ; N. Y. : Oxford University Press. viii, 266 p.

Koch, H. (1895) Der pseudo-epigraphische Charakter der dionysischen Schriften // Theologische Quartalschrift. S. 353-420.

Merton, R. K. (1972) Insiders and Outsiders: A Chapter in the Sociology of Knowledge // American Journal of Sociology. Vol. 78. No. 1. P. 9-47.

Zakharov, N. V., Lukov, Vl. A., Makarov, V. S., Gaydin, B. N. (2012) Digital Shakespeare in Russia [Электронный ресурс] // Информационный гуманитарный портал «Знание. Понимание. Умение». №5 (сентябрь - октябрь). URL: http://zpu-journal.ru/e-zpu/2012/5/Zakharov-etal_Digital-Shakespeare/ [архивировано в WebCite] (дата обращения: 25.12.2016).

Аата поступления: 27.07.2017 2.

Кузнецова Татьяна Федоровна доктор философских наук, профессор, академик Международной академии наук (Инсбрук, Австрия), трофессор кафедры культурологии Московского педагогического государственного университета. Адрес: 119571, Российская Федерация, г. Москва, пр-т Вернадского, д. 88. Тел.: +7 (495) 539-55-19. Эл. адрес: kult@mpgu.edu

Kuznetsova Tatyana Fedorovna, Doctor of Philosopy, Professor, Full member, International Academy of Science (IAS, Innsbruck, Austria), Professor, Department of Culturology, Moscow State Pedagogical University. Postal address: 88 Prospekt Vernadskogo, 119571 Moscow, Russian Federation. Tel.: +7 (495) 539-55-19. E-mail: kult@mpgu.edu

\section{Аля иичтирования:}

Кузнецова Т. Ф. Субъектность как атрибут экологии культуры [Электронный ресурс] // Горизонты гуманитарного знания. 2017, №4. URL: http://journals.mosgu.ru/ggz/article/view/576 (дата обращения: АА.мм.гггг.). DOI: 10.17805/ggz.2017.4.4 